Revista Iberoamericana, Vol. LXXIV, Núm. 223, Abril-Junio 2008, 531-557

\title{
HUELLAS DE LO REAL. \\ TESTIMONIO Y CINE DE LA DELINCUENCIA \\ EN VENEZUELA Y COLOMBIA ${ }^{1}$
}

\author{
POR \\ LuIS Duno-GotTBERG \\ Rice University \\ FORREST HYLTON \\ New York University \\ El testimonio contiene, no obstante, una laguna [...] Quien \\ asume la carga de testimoniar [...] sabe que tiene que dar \\ testimonio de la imposibilidad de testimoniar.
}

Giorgio Agamben

\section{LA HUELLA}

Representar lo Real es, por definición, un despropósito. Un corpus teórico extenso advierte lo fútil de esta empresa, cuando lo que se busca está caracterizado por escapar a cualquier forma de simbolización y los significados se postergan indefinidamente, perseguidos por precarios instrumentos como el lenguaje y la fotografía. Slavoj Žižek piensa el fenómeno en términos de una entidad monstruosa que comunica el horror o el trauma y que, sin embargo, está sólo presente mediante sus efectos (The Sublime... 163). Lo Real se manifiesta, en este sentido, en contradicción con la realidad y como un desplazamiento que señala los límites del lenguaje. Acaso por este motivo, y más allá de lo que digan las voces autorizadas de la teoría sobre las falacias de la representación, los espectadores acusan experiencias singulares en las que atisban, perturbados, "la huella de lo Real”.

Al decir esto, dialogamos implícitamente con la conocida reflexión de René Jara sobre el testimonio, donde propone que tal género se apoya en "narraciones de urgencia” (2-3). Es decir, historias que deben ser contadas a fin de sacar a la luz experiencias de represión, pobreza y violencia. Más que constituirse en una narrativa realista o fáctica, el testimonio pone en escena aquella historia que es irrepresentable y, con ello, devela trazas de lo Real.

Creemos que estas ideas podrían caracterizar de manera especial el testimonio literario y cinematográfico de delincuentes, donde percibimos no sólo una “narrativa de urgencia”, sino también un exceso de significación que desborda el texto y que resiste nuestros intentos por fijar la identidad del otro. No nacimos pa'semilla, en el caso colombiano; La ley de la calle y Soy un delincuente, en el caso venezolano, son buenos ejemplos de lo anterior. Digamos por el momento que, si bien es posible aprehender estos discursos mediante un aparato legal, médico, literario o incluso mediante la solidaridad que despiertan determinadas articulaciones políticas de la acción delictiva, existe un límite infranqueable marcado muchas veces por

\footnotetext{
${ }^{1}$ Agradecemos a Juana Suárez, Domingo Fuentes, Víctor Gaviria y Luis Ospina por sus sugerencias y comentarios iluminadores.
} 
la ultraviolencia desplegada por este sujeto testimoniante. Nos referimos a gestos difíciles de subsumir en la categoría del "bandido social” de Hobsbawm, y que vienen a constituir una otredad irreductible y radical. Siguiendo la imagen de Lacan, donde lo Real es como el golpe en la puerta que nos despierta de un sueño, podríamos decir que en estos textos, quienes llaman a nuestra puerta son sujetos desafiantes, que no se someten ni a la ley ni a la voluntad del lector: son las voces que descienden de las comunas de Medellín o los cerros de Caracas. En La ley de la calle, por ejemplo, un delincuente apodado Comegato nos dice, "frente a frente", de una existencia que nos resulta tanto ajena como amenazante:

... me encantaba un vaporón, entrarme a coñazos y a puñaladas. Estas marcas en los brazos y en el pecho son de esa época. Pero este gusano en las costillas y otro que me parte en dos una nalga y me baja hasta el muslo son marcas de guerra brava. Me las gané en el infierno, allá donde baja la mierda de esta sociedad, el retén de Los Flores. Floristería como la llama el hampa. (Duque, Muñoz 91)

Y en No nacimos pa'semilla, un sicario de veinte años parece regodearse en el ejercicio del asesinato, cuando afirma:

Lo que me da chispa es que me hayan encanado por cascar esa cosa. En el barrio me hicieron fiesta el día que lo maté [... Y Yo le tenía montada la cacería hacía días y siempre se me escapaba [...] Pero a los faltones [...] les doy con mucho gusto. Me lambo por pelarlos. (157)

Sin embargo, cierta pulsión o hábito de lectura pretende constantemente saldar la brecha que imponen estas subjetividades transgresoras, la cuales constituyen una "ininteligibilidad radical” (Jáuregui y Suárez 376). En una reflexión sobre el testimonio de Rigoberta Menchú, Doris Sommer advierte precisamente sobre "algunas costumbres de lectura autobiográfica en las cuales preferimos proyectar en la persona que escuchamos un yo presente y conocible" (135). Luego de poner en duda la generosidad de estas proyecciones de "presencia y verdad", la autora señala que dicho gesto permite "una apropiación no problematizada que acorta la distancia entre escritor y lector, ignorando así la insistencia del texto en el valor político de mantenernos a distancia” (135). Como veremos a lo largo de este trabajo, esta tensión acecha el consumo y distribución de los discursos de/sobre la delincuencia.

De la escritura a la imagen cinematográfica, la irrupción de estos sujetos es recurrente. El cine, quizás por esa compleja y esquiva relación con la realidad que en teorizaciones tempranas de André Bazin y Siegfried Kracauer fue definida en términos de "objetividad" y aun hoy es asunto de vigorosos debates (Cfr. Nichols, Carroll, Currie, Plantinga), ha constituido un espacio predilecto donde se "proyecta" 2 continuamente este tipo de otredades radicales. Mencionando apenas algunos ejemplos dentro de la producción latinoamericana tenemos: "Los olvidados” (México 1950, Luis Buñuel); "Río, 40 grados”, (Brasil 1955, Pereira dos Santos); “Gamín” (Colombia 1978, Ciro Durán); “Pixote” (Brasil 1981, Héctor Babenco); “Juliana” (Perú 1988, Fernando Espinoza y Alejandro Legaspi); “Johnny Cien Pesos” (Chile 1993, Gustavo Graef-Marino).

${ }^{2}$ Ver la sección IV, nota 10, para una aclaratoria en torno al uso de la noción de "proyectar" en el contexto de este estudio, y que se desprende de la cita anterior de Doris Sommer. 
En Venezuela y Colombia surgió todo un género, abarcando desde los registros de "la porno-miseria” hasta francos intentos por incorporar la voz del "criminal”. ${ }^{3}$ Dentro del último grupo, Clemente de la Cerda dirigió Soy un delincuente (1976) y Víctor Gaviria, Rodrigo D. No futuro (1990). Más allá de las diferencias que discutiremos más adelante, ambos directores incorporaron lo testimonial y crearon un espacio de representación para sujetos ultraviolentos. Se trata de trabajos que dan cuenta del mundo de la delincuencia y cuya proximidad con lo representado es tal que, en el caso colombiano, los actores naturales que las protagonizan no alcanzan a sobrevivir mucho más allá de la producción misma de las películas, al ser víctimas de la realidad que han traído a la pantalla.

Este cine ha sido recibido muchas veces con incomodidad; acaso porque los pronunciamientos de estas voces transgresoras se perciben, desde un espacio hegemónico, como una intrusión traumática. En Beyond the Pleasure Principle, Freud sugiere que debemos ver el trauma "as a consequence of an extensive breach being made in the protective shield against stimuli” (XVIII: 25). En este sentido, el estímulo que violenta el escudo -el superego- no es otro que un acto de habla que irrumpe desde el margen. Una posible reacción desplazaría la ruptura traumática hacia la risa o el asco y, sin embargo, seguimos descolocados. ${ }^{4}$ Cathy Caruth señala que el trauma "registers the force of an experience that is not yet fully owned” (151) y, ¿cómo apropiarse de una subjetividad como la que se despliega en los fragmentos citados más arriba? Slavoj Žižek dice que el trauma es, por definición, algo que no recordamos (¿“la laguna” de Agamben?), algo que se resiste a nuestra narrativa simbólica (On Belief 37).

Distinguir entonces la "huella de lo real” del “efecto de realidad”-descrito por Barthes y Althusser- resulta un asunto apremiante, más próximo a los problemas de la ética que a los de la teoría de la representación. John Beverley establece tal diferencia progresivamente a partir de algunas escenas de la picaresca española, donde identifica el simulacro del encuentro con lo Real, cuando el Lazarillo es golpeado brutalmente o el ciego se estrella contra un poste de piedra. Dichos personajes, dice Beverley, experimentan "lo Real” y no el "efecto realidad":

[...] the Real, at least in its effects, is not too different from what the Russian Formalist used to call ostranenie or defamiliarization. Perhaps intending the pun with the French touché, Lacan himself uses the Aristotelian category of tuché or "fortune" to describe the (sudden, fortuitous) "encounter with the Real," as he puts it: the knock on the door that interrupts our dream (either as outside the dream or as another reality in it), for example,

\footnotetext{
${ }^{3}$ La noción de "porno-miseria" fue sugerida por Luis Ospina y Carlos Mayolo como una crítica a cierta producción cinematográfica que representaba el miserabilismo latinoamericano, en función de su venta como mercancía tremendista. La distinción que realizamos en este capítulo busca separar estas representaciones, de otras que pugnan por crear espacios de agenciamiento para sujetos marginados. Esta segunda posibilidad se resiste al consumo fácil de subjetividades-mercancías abyectas y, como sugieren Carlos Jáuregui y Juana Suárez, plantea una ética de la representación que rechaza el borramiento de la otredad (389).

${ }^{4}$ Recordemos que la repulsión que produce lo abyecto permite que el sujeto lidie con el Otro sin desintegrarse. Es el modo en que el sujeto mantiene su integridad al confrontarse con el orden semiótico.
} 
or, more prosaically perhaps, the piece of gum or dog shit that sticks to the sole of our shoe resisting all attempts to dislodge it. (274)

Concientes de que, como advierte Beverley, cada espacio simbólico tiene su Real, es decir que se trata de una categoría relacional, dejamos pues de lado el vasto tema del "realismo" e incluso de la "representación", para pensar en instancias discursivas que propician una apertura velada de sentidos, los cuales parecen usualmente postergados por su condición traumática, abyecta o incomprensible. Más acá de la realidad se abisma lo Real, eludiendo la sujeción del significante y, sin embargo, dejando trazos en la experiencia. Pensamos en instantes en los que la imaginación no consigue unir el acontecimiento a un concepto que lo abarque y contenga. Ante la mirada del espectador -o desde ésta- se proyecta un exceso que sólo comunica la resistencia a ser cabalmente representado. Esa opacidad y su efecto puestos en escena por intervenciones en lo literario o cinematográfico por parte de sujetos marginados, excluidos, violentados y violentos, es lo que llamamos aquí "la huella de lo real”.

\title{
II. SOY UN DELINCUENTE: UNA NARRATIVA INDÓCIL O RESISTENTE
}

\begin{abstract}
Escribo y escribo y en una tarde lleno todo el cuaderno. Después leo lo escrito y encuentro que son puras maldades que digo que haré a los compañeros y a los guardias, y entonces cojo el cuaderno y lo rompo [...]

Ramón Antonio Brizuela
\end{abstract}

El fragmento anterior proviene de lo que hasta ahora se ha considerado como el testimonio de Ramón Antonio Brizuela, un asaltante caraqueño que escribió la historia de su vida durante los años setenta, antes de morir abaleado durante un robo. El libro, publicado bajo el título Soy un delincuente gozó de un gran éxito en Venezuela, logrando catorce ediciones y una adaptación cinematográfica, seguida de una secuela. La historia del manuscrito es fascinante y será abordada en un momento; interesa, por ahora, el problema planteado por el éxito de este testimonio en el mercado editorial y en las salas de cine de Venezuela. Ello puede ser leído en el contexto de la polémica en torno a qué hacemos y, sobre todo, qué nos es posible hacer, cuando leemos este tipo de narrativas producidas desde la subalternidad.

Hagamos memoria: uno de los elementos que impulsaron la discusión teórica sobre el testimonio fue la posibilidad de pensar nuevos sujetos de enunciación previamente marginados, los cuales, a su vez, articulaban una política y una poética de la solidaridad (Jara, “Prólogo”; Beverle, Del Lazarillo...; Yúdice, “Testimonio y concientización”). Este proyecto fue luego problematizado a finales de los noventa por autores como Elzbieta Sklodowska y Alberto Moreiras. Éste último advierte contra la fetichización del testimonio, surgida de lo que denomina "una práctica aurática de lo postaurático". Se refiere a una praxis crítica que anularía la agencia del sujeto testimoniante al ponerlo en escena mediante un gesto prosopopéico (darle voz a los muertos) y desde el espacio institucionalizado de la 
literatura. ${ }^{5}$ Este riesgo, que se vincula estrechamente al consumo del género mediante su canonización, había ya sido sopesado por Beverley en su propuesta "contra la literatura”. Moreiras, por su parte, retoma la discusión de Doris Sommer, destacando el recurso del secreto (aquello que el testimoniante se reserva ${ }^{6}$ ) como mecanismo textual que afirma una diferencia insalvable, irreductible: "the secret is the (secret) key to the real as unguarded possibility”, señala luego Moreiras (206). El autor concluye que la labor crítica permanece, sin embargo, en el impasse del la restitución (no necesariamente mimética) de un objeto abyecto y, con ello, establece una mediación jerárquica (210).

A la objeción de Moreiras podríamos responder siguiendo nuevamente a Beverley, quien observa que "el efecto deconstructivo" de éste, termina por suplantar "el efecto testimonio". Por ello quisiéramos volver sobre Soy un delincuente para observar, en todo caso, los límites de la apropiación crítica frente a un texto que deviene indócil y resistente, incluso al "efecto deconstructivo".

Es difícil estudiar la recepción de Soy un delincuente, cuyo éxito entre los lectores contrasta con la perplejidad de los críticos venezolanos. "Monstruosidad literaria", lo llamó Aníbal Nazoa, luego de señalar que si el libro "no colma el asco, entonces estamos perdidos” (El Nacional, 27/7/74). Las ventas, sin embargo, dan cuenta de un fenómeno que, en una conversación con Domingo Fuentes, el editor del testimonio, nos fue explicado en términos de una identificación vicaria de los lectores con una realidad amenazante que caracteriza la vida caraqueña. De ser correcta esta interpretación, los lectores se aproximaron al relato de Brizuela con una mezcla de curiosidad y repulsión. El texto les permitía consumir con seguridad a un sujeto cuya existencia ponía en juego "la vida y los bienes de los ciudadanos”, como suelen decir los reportes policiales. Se trata de la posibilidad de proyectar con seguridad una mirada ortopédica sobre sujetos que habitan los márgenes de la ciudad de Caracas; sujetos que descienden de los cerros, “desplegando su violencia sobre los ciudadanos del valle”.

Nos interesa discutir brevemente una de las reacciones al testimonio de Brizuela, publicada en una revista de circulación masiva, la cual condensa el "pánico moral”7 con el reconocimiento de la utilidad del libro en función de una política posiblemente represiva. Transcribimos un fragmento más o menos extenso, ya que el desagrado de la articulista resulta precisamente sintomático de este complejo efecto del testimonio de la delincuencia que, como veremos también en el caso colombiano, oscila entre la imposibilidad de concebir el mundo representado, el rechazo, el temor y, por otro lado, el reconocimiento de la "utilidad de lo testimonial” dentro de una política de control de la violencia y -menos frecuentemente- de una transformación de las bases estructurales de ésta.

\footnotetext{
5 “'In prosopopoeiac representation solidarity turns into a production of abjection where the producing agency, testimonio criticism, retains an aura that has been literally sucked off the testimonial subject, now abjected" (Moreiras 202).

6 "Sigo ocultando lo que yo considero que nadie sabe, ni siquiera un antropólogo, ni un intelectual, por más que tenga muchos libros, no saben distinguir nuestros secretos” (Rigoberta Menchú 196).

7 "A condition, episode, person or group of persons emerges to become defined as a threat to societal values and interest” (Cohen 1).
} 
Este es un libro horrible. Terrible también, porque descubre una serie de lacras que la gente normal de nuestra sociedad -que afortunadamente sigue siendo mayoría- preferiría no conocer. No es sólo su crudeza, que muchos calificarán de inmoralidad, ni su lenguaje -que no es por cierto ni agradable ni literario- sino que nos descubre ese submundo, o si lo prefiere, esa sub-cultura, donde la delincuencia, la prostitución y el mundo de las drogas, son una manera de vivir corriente para un montón de seres humanos, ¿humanos? que nunca conocieron otra. Ese submundo no tiene relación ALGUNA con el nuestro, no se sigue por las reglas del juego que nosotros jugamos y no precisamente porque no quiere seguirlas o porque se rebela contra ellas, sino porque sencillamente las ignora. No las conoce, nunca le han llegado y por lo tanto, para ella no existen.... Probablemente causará un escándalo, ojalá que así sea, a fin de que los encargados de velar por nuestra sociedad tomen al fin conciencia -y toda clase de medidas- para que la lacra que este libro descubre no continúe extendiéndose. (Revista Élite, 19/7/74)

Juana de Ávila, la autora de la reseña, revela su horror ante la emergencia de lo que percibe como una patología ajena a su mundo. Las mayúsculas dan cuenta de su rechazo hacia experiencias y sujetos cuya humanidad queda en dudas y cuya existencia algunos preferirían no conocer. Luego de señalar el problema de "las reglas del juego" social violentadas por sujetos como Brizuela, advierte la utilidad del texto que, a partir del escándalo, llevaría a "los encargados de nuestra sociedad" a tomar "toda clase de medidas". En este sentido, es interesante un comentario publicado en la Revista Resumen, donde se sugiere que estos materiales serán de utilidad para el Ministerio de Justicia y para la reforma de la Ley del Sistema Penitenciario (Revista Resumen 37, 21/7/74). En definitiva, se trata de controlar la proliferación “sujetos desechables”, de "basura social”, mediante un discurso de profilaxis que, de modo fetichista, esconde la lógica y la violencia del capital (véase Jáuregui y Suárez 367-369).

Soy un delincuente permite de este modo el consumo de una identidad abyecta que, a su vez, resulta instrumental en la constitución de la identidad del sujeto hegemónico, ese que existe bajo la figura de un lector-ciudadano o un letrado solidario. Dicha operación define un espacio de legitimidad para aquellos que leen sobre la amenaza que viene desde los márgenes de la ciudad. Mecanismo de auto-afirmación éste que, sin embargo, siguiendo las reflexiones de Kristeva, no se resuelve necesariamente en una apropiación de lo abjecto, pues no alcanza a anular un espacio ininteligible donde colapsa el significado. Dice Kristeva:

The abject has only one quality of the object-that of being opposed to $I$. If the object, however, through its opposition, settles me within the fragile texture of a desire for meaning, which, as a matter of fact, makes me ceaselessly and infinitely homologous to it, what is abject, on the contrary, the jettisoned object, is radically excluded and draws me toward the place where meaning collapses. (13)

Invitamos a leer este movimiento hacia el colapso de la significación como uno de los efectos de este tipo de testimonio, y como una traza de la intrusión traumática de una otredad radical. Al mismo tiempo, es posible ver aquí una instancia de resistencia que impide anular al sujeto subalterno y que obstaculiza la confiscación de su agencia. Veamos por un momento cómo opera ello en el caso de Brizuela, pues sería un error suponer que los lectores logran apropiarse de la totalidad de su discurso. 
Soy un delincuente revela las trazas de una confrontación por el derecho a la palabra. Esa pugna marca la textura misma del discurso, donde se observan paratextos diversos que pretenden controlar la significación del testimonio (Dabove 37-52). De este modo se suman una introducción, un glosario de la jerga delincuencial, una serie de fotografías y recortes de prensa. Sin embargo, todo ello no logra aplanar el discurso de Brizuela. En primer lugar, porque como sugiere en el epígrafe que citamos más arriba, "las maldades que piensa” no siempre quedan registradas, pues él se ha encargado de romper muchas páginas. El sujeto testimoniante administra así su historia, poniendo límites a nuestra posibilidad de apropiarnos de la totalidad de su discurso.

Existe aún otro elemento que revela la complejidad de Soy un delincuente en tanto texto indócil; tiene que ver con lo que describimos en términos de rugosidades o desniveles en el relato, y que ahora podemos explicar por el origen polifónico del texto, y por el fracaso del proyecto literario que trató de aplanar los testimonios que lo habitan. Una evidencia de estas rugosidades se encuentra en los lenguajes de "múltiples Brizuelas”. Se registran así variaciones que van del discurso lírico del malandro enamorado $(31,63)$, a la pulsión del violador (133, 170); del ladronzuelo (178), al gran jefe de bandas que reflexiona en términos estratégicos y considera los problemas de la cultura y la política (230-333).

Soy un delincuente es en realidad un testimonio de testimonios: Brizuela, el personaje, nunca existió. El manuscrito que llegó a Domingo Fuentes, el editor, fue producido por un tal Juan Sebastián Aldana, a su vez seudónimo de Gustavo Santander. ${ }^{8}$ Sin embargo, como veremos en lo sucesivo, ello no anula el efecto testimonial de la obra. Es Santander quien se encargó de compilar la historia de varios delincuentes en una serie de cuadernitos, los cuales repartió a sus compañeros de celda durante su propio presidio. Santander, en este sentido, no fue exactamente un intelectual que se acercó a los delincuentes con la mirada de la porno-miseria o con un cómodo gesto redentor. Fue, por el contrario, un escritor que existió al margen de la institución literaria venezolana y quien, a raíz de una compleja historia personal, sufrió el presidio junto a sujetos como Brizuela.

Volvamos pues a la multiplicidad de delincuentes que compusieron sus historias en los cuadernillos cedidos por Santander, quien intentó sin éxito unificarlos bajo la figura de Brizuela. Habría que decir primero, que una lectura atenta de Soy un delincuente anunciaba ya esta pluralidad de voces. Es claro, sobre todo si comparamos la primera, la segunda y la tercera parte del libro, que no existe una voz homogénea detrás el personaje principal: hay muchos Brizuelas. Esta irregularidad es, sin embargo, uno de los aspectos más interesantes de la obra. Creemos que allí donde fracasa la literatura, triunfa el testimonio: la imposibilidad de subsumir varias voces bajo la figura de un personaje constituye un éxito de esas voces diversas y complejas que no se sujetan a una imagen homogénea del delincuente.

Fracturada la imagen monolítica del trasgresor, surge entonces un registro diverso que abarca desde el "bandido social” hasta el ladrón que se embelesa con su botín y que no hace más que aspirar a la reproducción de las estructuras que lo oprimen. Hay un Brizuela que desea robar cualquier cosa pequeña, y hay otro que elabora una detallada lista de lecturas,

${ }^{8}$ Esta afirmación es producto de nuestras investigaciones en Caracas y viene a cuestionar un argumento ampliamente difundido en el país sobre la existencia de este personaje. Agradecemos a Domingo Fuentes, a la flia. Santander y a José Roberto Duque por su generosa ayuda para obtener esta información. Entrevistas personales con Luis Duno-Gottberg (2002, 2004). 
no para constituirse en escritor, sino para devenir un mejor y más efectivo ladrón: éste sabe que hay que saber aparentar ante la ley y, para ello, la literatura es muy útil.

Un delincuente que quiera superarse tiene que buscar buenos libros que le den la experiencia de la vida; porque en los libros se sabe cómo ha sido la vida de los grandes delincuentes del mundo, que muchas veces se han tenido por sanos y resulta que ha sido porque no se les conoce bien, y en los libros sí se encuentra dicho qué es lo que han sido. (291)

Soy un delincuente es así un "testimonio de testimonios", que al no consolidarse en una narrativa literaria homogénea y al deconstruir la institución misma de la literatura (vista dentro del texto como recurso para la simulación y el delito), pone en escena la resistencia de la narrativa delincuente o lo que hemos llamado la "huella de lo Real".

\section{Proyectar LA DELinCUenCia ${ }^{9}$}

La comparación de dos películas que han devenido clásicos del cine sobre la delincuencia en Venezuela y Colombia permite pensar en las dificultades que conlleva la proyección de cierto tipo de otredad radical. Soy un delincuente (1976), del venezolano Clemente de la Cerda, y Rodrigo D. No futuro (1990), del colombiano Víctor Gaviria, podrían parecer a primera vista dos proyectos idénticos, centrados en el tema de la violencia urbana. Sin embargo, más allá de que ambas obras coincidan en trabajar con elementos testimoniales y actores naturales, hay en ellas un resultado distinto, a partir de la interacción que establecen con el mundo de la delincuencia.

Como mostraremos más adelante, en la primera observamos una elaboración verosímil, ${ }^{10}$ aunque en ocasiones exterior y "gesticulante" de este universo de lo ultraviolento; mientras que en la segunda se evidencia un compromiso más claro con los sujetos marginados a fin de que dicten el desarrollo de sus propias historias. En esta sección analizaremos ambas películas para discutir las dificultades que conlleva la transposición cinematográfica de “textos resistentes"; es decir, de los testimonios de la delincuencia.

En apenas veinte años, Clemente de la Cerda produjo de manera vertiginosa once películas: "Isla de sal” y "El rostro oculto" (1964), "Sin fin” (1971), “Cahuramanacas" (cortometraje, 1971), Soy un delincuente (1976), "El reincidente” y "Compañero de viaje” (1977), “El crimen del penalista” (1979), “Los criminales” (1982), “Retén de Catia” y “Agua que no has de beber” (1984). Si bien esta labor dio por fruto una de las películas

\footnotetext{
${ }^{9}$ Aprovechamos la polisemia de la palabra "proyectar" para referirnos a la coexistencia de una doble articulación en algunas manifestaciones de este cine. Por un lado, nos referimos a la significación más inmediata de dar a conocer un cuerpo a través una técnica cinematográfica. Por el otro, nos referimos a que dicho acto responde a un proyecto o plan que persigue dar visibilidad a un sujeto social excluido. Cuando el propósito corresponde a un diseño que surge desde un espacio distinto al del mundo representado, existe la posibilidad de que lo diseñado sea la subjetividad misma del delincuente, desde un lugar hegemónico. Esta segunda articulación avanza en el territorio de la "porno-miseria", la moralina o el "pánico moral" (Cohen).

${ }^{10}$ Verosímil, en el sentido de aspiración a producir un “efecto” de realidad. Más adelante compararemos este "efecto realidad" con lo Gaviria denomina "voluntad realista".
} 
más exitosas en la historia del cine venezolano, ${ }^{11}$ la recepción crítica fue marcadamente negativa. La intelectualidad del país lamentaba un cine "de putas y ladrones", que no elaboraba propuestas visuales ni discursos poéticos. ${ }^{12}$ Desde una perspectiva ilustrada y con frecuencia elitista, reaccionaron con repudio a la representación de sujetos y espacios que resultaban invisibles en el panorama de una cultura nacional que, nutriéndose de la renta petrolera, se embarcaba en un ambicioso proceso de modernización. ${ }^{13}$ En este sentido, la suerte de Clemente de la Cerda es afín a la de Gustavo Santander, tal como hemos afirmado más arriba: ambos gozaron de un gran éxito entre el público, mientras permanecieron al margen de la "ciudad letrada”, de los circuitos “más legítimos” de la cultura nacional.

Soy un delincuente, el cuarto largometraje realizado por Clemente de la Cerda, fue producido bajo el auspicio del estado y en los años de la "Venezuela saudita"; sin embargo, la película se aparta de la euforia de esos tiempos y se propone la transposición del testimonio de José Antonio Brizuela. ${ }^{14}$ En pleno auge petrolero, el director pone en la pantalla a sujetos que han sido excluidos de la bonanza: delincuentes, marginales, prostitutas y drogadictos. ${ }^{15}$ Si bien ya existía una tradición dentro del cine venezolano que abordaba el tema de la delincuencia y la marginalidad, como en el caso de La escalinata (César Henríquez, 1950) y El Caín adolescente (Román Chalbaud, 1959), Clemente de la Cerda trajo a la pantalla una crudeza inédita, incorporando el habla del "malandro" y el realismo de un reparto integrado por algunos actores naturales y abundante filmación en exteriores.

El camino que lo lleva a la realización de Soy un delincuente (1974) se construye con esfuerzos personales y tropiezos mientras va educándose en el oficio de cineasta, mediante la realización de comerciales para televisión. Su segundo largometraje, El rostro oculto (1965), adapta el cuento de Mauricio Oderman, Los drogómanos, en un proyecto poco feliz: un guión que tiende a ser forzado y un tono moralista signan las limitaciones de la película. Ambretta Marrosu escribe:

El caso de El rostro oculto es más bien similar al de la gran serie delincuencial que arranca con Soy un delincuente y en la cual el hecho de escoger un tema de "impacto" no impide que constituya al mismo tiempo una preocupación radicada y sincera del autor. El rostro oculto, sin embargo, presenta una insólita genuflexión hacia afuera, ya no dirigida al gusto del público, sino a la moral pública, es decir, la institucionalizada, no sólo con el esfuerzo aparente de diferenciar entre depravados buenos y malos, víctimas y verdugos, sino sobre todo colocando, al comienzo y al final de la película, el texto de un autor

\footnotetext{
${ }^{11}$ En su momento, Soy un delincuente superó en Venezuela el récord de taquilla de dos de los grandes éxitos de Hollywood, Tiburón y E.T. (King 309).

${ }^{12}$ Un excelente análisis de la recepción letrada de Soy un delincuente aparece en el trabajo inédito de Magdalena López, “La estética del 'balurdo': la propuesta de los filmes Soy un delincuente y Reincidente".

${ }^{13}$ Son los años de la Fundación Gran Mariscal de Ayacucho, creada por el estado venezolano en 1975 para formar cuadros profesionales en universidades extranjeras.

${ }^{14}$ Cabe decir que los beneficios de la bonanza petrolera no fueron ajenos a la producción misma de la película, la cual recibió apoyo de Corpoturismo y Corpoindustria.

${ }^{15}$ Magdalena López elabora una interesante propuesta que alinea la obra de Clemente de la Cerda con la picaresca española, a partir de la coincidencia entre los modelos rentistas del imperio español y la Venezuela petrolera.
} 
probablemente norteamericano, que embiste muy dignamente contra el tráfico de drogas. Tal énfasis parece pretender el ocultamiento de las muchas contradicciones que, frente a esa moral social, presenta la película... (Cisneros 136)

Esas contradicciones que observa Marrosu en la película surgen del choque entre un deseo por presentar experiencias sociales consideradas ilegítimas y peligrosas; mientras que al mismo tiempo se satisface la fascinación que despierta la puesta en escena un "mundo prohibido”. Se trata del doble movimiento que produce la interacción con lo abyecto, y que en este caso oscila entre el consumo de "un tema de impacto", como dice Marrosu, y su contención, mediante una serie de admoniciones que se esconden bajo diálogos y paratextos moralizantes. De este modo se proyecta el mundo del delincuente, en el doble sentido que hemos mencionado al inicio: se lo muestra y se lo reconforma disciplinariamente.

Soy un delincuente anuncia una transformación, a pesar de no constituir una ruptura total con la estética heredera del neorrealismo italiano que percibimos en La escalinata, ni con las propias aproximaciones iniciales del director al tema de la marginalidad. En efecto, Clemente de la Cerda todavía apela al melodrama entretejido con parlamentos moralizantes; sin embargo, el efecto general de esta nueva película es uno de transgresión: el espectador es "asaltado" por la presencia de un sujeto marginal que rinde testimonio de su existencia, mediante un lenguaje que tendía a estar ausente de las pantallas de cine. ${ }^{16}$ Sobre todo, de la Cerda parece acertar en la construcción de una perspectiva que desplaza la mirada hacia un espacio periférico, desde donde se aspira a elaborar la narrativa. Todo ello contribuyó a una doble recepción: la de los circuitos oficiales de la cultura, que rechazaron su carácter "chocante” e "inapropiado"; y la del público general, que acudió masivamente a las salas de cine. ${ }^{17}$

Como hemos señalado, este nuevo tono desarrollado por Clemente de la Cerda no deriva necesariamente de los recursos realistas - que ya habían aparecido en los antecedentes del cine venezolano sobre la delincuencia-, sino más bien del intento por construir una "mirada desde la periferia” ("mirada al margen”" $)$. Esto se logra mediante la colocación de la cámara en un locus que podríamos caracterizar, aunque sólo momentáneamente, como “subalterno". En este caso se elabora una “mirada objetiva desde el margen”, por cuanto no se trata propiamente de la visión del personaje delincuente, ni tampoco de una narración omnisciente ajena a éste. Digamos que la cámara "registra” ahora desde el barrio.

La película comienza con una toma abierta del amanecer, visto desde el oeste de la ciudad de Caracas. ${ }^{19}$ Simultáneamente se superpone un texto introductorio que, como veremos,

\footnotetext{
${ }^{16} \mathrm{El}$ tema del lenguaje resulta fundamental para comprender la creación de espacios de resistencia por parte del sujeto delincuente. Una queja frecuente ante el cine de Clemente de la Cerda es la "procacidad" del lenguaje de sus personajes. En el caso de Víctor Gaviria encontramos una conciencia clara de que "la ininteligibilidad radical [del lenguaje] es inseparable del acto de representación participativa" (Jáuregui y Suárez 377). La factura de su cine incorpora así un habla que también ha suscitado el rechazo de cierta audiencia colombiana.

${ }^{17}$ Para la recepción de la película, ver el trabajo de López.

${ }^{18}$ Véase Duno-Gottberg.

${ }^{19}$ Caracas es un angosto valle que se ha desarrollado en sentido oeste/este. Dicho eje recoge asimismo una espacialización de la pobreza, que a pesar de rodear buena parte del valle, cuenta con importantes
} 
parece representar una perspectiva opuesta a aquella encarnada por la cámara. Miramos entonces desde lo alto del barrio. Vemos la estructura del Elicoide, uno de los proyectos arquitectónicos inconclusos de la dictadura perejimenista. Alrededor de este "monumento" a la modernidad venezolana, se extienden otros: los ranchos ruinosos de la democracia. El inicio no sólo constituye un comentario sobre la historia de la modernización del país, sino que acierta en colocar al espectador adentro de los anillos de miseria que rodean a la capital. Aunque la narración apenas adopte la perspectiva del delincuente, podríamos convenir que este tipo de "tomas objetivas desde el margen" constituye un intento por abrir un espacio de representación para la otredad radical del delincuente.

Contra este acierto en desplazar la mirada hacia el margen, sin embargo, se presentan luego el sonido extra-diegético -una serie minimalista crea una atmósfera de tensión- y un paratexto que recoge comentarios marcadamente ajenos al mundo del delincuente. Esta combinación de elementos produce una dinámica perfectamente ajustada a la tensión que observamos en el testimonio compilado por Gustavo Santander entre la voz del delincuente y la voz letrada. En el caso de la película, el texto que acompaña las tomas iniciales advierte:

Lo que ustedes verán es la narración testimonial basada en la vida de Ramón Antonio Brizuela; como tal muchos la sentirán llena de gran violencia. Encontrarán un lenguaje necesariamente obsceno siendo esto una realidad que se debe respetar para lograr la autenticidad de esta historia en lo que le da todo el valor documental [...] La mayoría de los protagonistas no son actores profesionales, colaboró gente de los barrios y por eso se notará que no es un trabajo sumamente elaborado, esto fue hecho ex profeso con el fin de producir un clima totalmente natural. (Soy un delincuente)

Es obvio que aquí se articula un lugar de enunciación ajeno al mundo de Brizuela. Sin embargo, esto no hace más que reforzar un contrapunto que se repite a lo largo de la película, entre espacios/voces de la periferia y espacios/voces hegemónicos.

El énfasis en establecer una mirada desde el margen vuelve hacia el final de la película, ahora bajo la forma de un interesante paralelo entre dos tomas abiertas de la ciudad de Caracas. La primera se levanta desde La Plaza Altamira, en una zona de clase alta al este de la ciudad, y viaja en dirección oeste. Aquí se utiliza una cámara alta sobre el cuerpo, cada vez más pequeño, de un asaltante muerto. Dicha secuencia culmina en un gran plano general donde se empequeñece el objeto de la mirada. Luego surge la perspectiva opuesta, cuando vemos desde el oeste, desde el barrio, la llegada del protagonista que ha perdido a su compañero en un violento enfrentamiento con la policía. La mirada culmina aquí con planos medios y close ups. Estamos cerca de Brizuela. Justo antes de que aparezcan los créditos, escuchamos un último paratexto que se introduce bajo la forma de sonido diegético: la radio suena en el fondo de la escena, reverberando en el barrio y comentando el aumento de los precios del petróleo. La película ha tratado de mostrarnos la Venezuela saudita desde el otro lado de la bonanza, para ello combina perspectivas desde el margen y sobre el margen.

barriadas en el extremo oeste. Como veremos más adelante, esta cartografía resulta particularmente relevante en Soy un delincuente. 
Del este al oeste, las miradas que encontramos en Clemente de la Cerda parecen conjugar posiciones definitivamente antagónicas: las del centro y la periferia.

Cabe decir finalmente que la transposición cinematográfica del testimonio de BrizuelaSantander por parte de Clemente de la Cerda revierte sólo a medias la borradura del sujeto delincuente. Como hemos visto, el testimonio original adquiere riqueza debido a la imposibilidad de anular la pluralidad de voces que lo habitan. Sin embargo, en el proceso de transposición del texto literario-testimonial al texto fílmico, la polifonía del primero queda aplanada bajo la presencia de un personaje único que encarna al delincuente. Esta unificación de las múltiples y heterogéneas voces que se pronunciaban desde el margen es un logro importante para la unidad de la caracterización de Brizuela como personaje cinematográfico y, sin embargo, constituye una pérdida de la traza de lo Real. En efecto, todo parece indicar que es en el registro de una imposibilidad donde hemos de encontrar el testimonio de aquello que no puede ser representado.

Víctor Gaviria parece encarnar de manera promisoria ese momento que celebra Ruby Rich cuando dice: “¡El Nuevo Cine Latinoamericano ha muerto, larga vida al Nuevo Cine Latinoamericano!” (Rich 294). En efecto, el trabajo de este director marca importantes transformaciones que lo ubican como uno de los cineastas más importantes del momento. A su vez, no es ajeno a la tradición discursiva que venía gestándose desde finales de los años cincuenta y que cristalizó en una notable producción en las dos décadas subsiguientes. Aquél fue un período de manifiestos, militancia revolucionaria e intelectuales de vanguardia. En Cuba se llamó a realizar un "cine imperfecto”; en Brasil se cultivó “una estética del hambre” y en Argentina se reclamaba un "tercer cine”.

Algunos textos de esa época, que han devenido ya clásicos en la historia del cine latinoamericano, como Cine y subdesarrollo (1962) de Fernando Birri; Hacia un Tercer Cine (1969) de Fernando Solanas y Octavio Getino, Estética de la violencia (1971) de Glauber Rocha; Teoría y práctica de un cine junto al pueblo (1979), de Jorge Sanjinés y el Grupo Ukhamau, permiten intuir una filiación entre estos proyectos y el trabajo desarrollado décadas más tarde por Gaviria. Salvando las distancias, podríamos identificar por lo menos tres ejes de coincidencias, que luego revelarán sus particularidades innovadoras para el caso que nos ocupa: 1) el deseo común de movilizar solidariamente la conciencia del espectador; 2) la intención de incorporar un imaginario y un sujeto social que han sido relegados por los procesos de explotación -neocolonial o global-y, finalmente, 3) la voluntad realista. ${ }^{20}$

Estos elementos se encuentran estrechamente vinculados. Fernando Birri, por ejemplo, se preguntaba qué tipo de cine necesitan los pueblos latinoamericanos y respondía: "Un cine que les dé conciencia, toma de conciencia; que los esclarezca (...)” (Hojas de cine). Este compromiso se vinculaba a su vez al propósito de hacer un cine realista y popular, en el sentido de que su realización se nutría de las aspiraciones y reclamos históricos del pueblo. Gutiérrez Alea escribió al respecto: “Cuando hablamos de un cine popular no nos referimos al cine que simplemente es aceptado por el pueblo, sino a un cine que además exprese los intereses más profundos y más auténticos del pueblo” (Gutiérrez Alea 15). Tal

\footnotetext{
${ }^{20}$ Tomo aquí prestada la expresión que emplea el propio Gaviria para aludir al tema, cuando se refiere
} a su "voluntad realista". 
propósito es afín al cine realizado en Bolivia por Jorge Sanjinés, quien distingue claramente entre un "cine sobre el pueblo" y un "cine del pueblo"; optando por el segundo término y celebrando un "cine colectivo", donde actores naturales participan en la elaboración del libreto. Realismo y compromiso popular van así unidos a la función de movilizar políticamente a la audiencia.

Estas ideas no son ajenas a Víctor Gaviria quien, por su parte, exige que el espectador mire hacia zonas no cartografiadas en el diseño urbano de Colombia (véase Kantaris); haciendo que aquellos sujetos desdibujados por la violencia del aparato estatal o la delincuencia se hagan visibles por medio de su propia intervención en los guiones de las películas. Desde una posición distinta a la que caracterizó al intelectual de los años sesenta y setenta, el proyecto de Gaviria es también esclarecer la conciencia y abrir un espacio para un pronunciamiento desde lo subalterno: "Busco desenfocar las miradas, proponer otras y cambiar la relación que se tiene con personas que no existen como interlocutores", afirma en una entrevista (Jáuregui 234).

Es interesante destacar aquí el tránsito de un compromiso con "el pueblo” y "lo popular" -nociones que han sido recurrentes en los discursos nacionalistas de izquierda en América Latina y que persiguen formas controladas de inclusión-, a la idea de una relación con "lo subalterno", entendida como vínculo con “aquél que no puede hablar” o más bien, aquél cuya voz no es escuchada cuando se pronuncia desde un lugar no hegemónico. Al incorporar a "personas que no existen como interlocutores", al cederles un espacio en la factura cinematográfica a fin de que se expresen desde el lugar al que han sido relegados por procesos históricos de exclusión, Víctor Gaviria desplaza sutilmente la centralidad del intelectual que pretende juzgar y/o orientar a los desposeídos. Creemos que es aquí donde se revela una diferencia importante frente al cine social que le precedió: en la aparición de un director que asume una postura menos obliterante dentro del proceso creador y, con ello, frente a los procesos políticos y sociales.

La idea de una vanguardia cinematográfica que constituía a su vez una vanguardia política fue recurrente entre varios directores del Nuevo Cine. Con diversos grados, observamos que éstos se presentaban como guías de una masa alienada, como sujetos privilegiados que esclarecerían las conciencias de los oprimidos. Todo ello parece ausente en Gaviria, quien plantea su labor en términos de un diálogo, un pacto con quienes son sistemáticamente silenciados, borrados. En este acuerdo, el director no asume el travestismo populista haciéndose pasar por el Otro, ni el lugar aventajado del líder revolucionario.

Otro punto de confluencia entre el Nuevo Cine Latinoamericano y la obra de Víctor Gaviria lo constituye el propósito expreso de poner en escena “la realidad”. Es bien conocida la experiencia de Tomás Gutiérrez Alea, Fernando Birri, Julio García Espinosa y Gabriel García Márquez en el Centro Sperimentale de la Universidad de Roma, donde entraron en contacto con el cine neorrealista italiano, el cual dejó a su vez una impronta en América Latina. La meta era entonces el realismo; así define Birri el objetivo fundamental del nuevo cine argentino producido en el Instituto de Cinematografía de la Universidad Nacional (Hojas de cine). Gaviria parece rendir también homenaje al neorrealismo italiano con el título de su primer largometraje, Rodrigo D. No futuro, el cual evoca Umberto D. de Victorio de Sica. Sin embargo, la voluntad realista que observamos en el director colombiano no puede 
entenderse en los mismos términos que caracterizan la estética neorrealista. No hay aquí una ingenua confianza en la mimesis, ni como hemos señalado, una postura paternalista frente al mundo de los oprimidos. Hay, por el contrario, un compromiso ético con la producción de un espacio donde sujetos subalternos articulen su propio discurso, revelando trazos de aquello que, por irrepresentable, deviene una huella de lo Real.

Ana M. López comenta las transformaciones ocurridas cuando se desvanece la confianza en la capacidad de la cámara para reproducir la "verdad" y capturar "la esencia nacional" sin mediación alguna; dando paso a concepciones más complejas de la representación:

\begin{abstract}
"Realism", no longer seen as tied to simple perceptual truth or to a mimetic approximation to the real, was increasingly used to refer to a self-conscious material practice. The cinema's powers of representation-its ability to reproduce the surface of the lived world-were activated not as a record or duplication of that surface, but in order to explain it, to reveal its hidden aspects, to disclose the material matrix that determined it. This process was, furthermore, not an end in itself... But was articulated as part of a larger process of cultural, social, political, and economic renovation. (“At the Limits..." 407-08)
\end{abstract}

En la entrevista citada antes, Gaviria reflexiona ampliamente sobre el tema del “realismo”, esbozando dos conceptos que resultan primordiales para comprender la originalidad de su proyecto: la "voluntad realista” y el "imperativo ético". Estos dos elementos reclaman una práctica cinematográfica singular que determina los procedimientos técnicos y el alcance político de su cine. La participación de actores naturales y la elaboración colectiva del guión responden a una "voluntad realista” que asume las dificultades de su propósito y se distancia de cualquier pretensión de objetividad o calco. ${ }^{21}$ Esta se entiende más bien a partir de una ética de la representación, que impone el compromiso de llevar a la pantalla experiencias que resultan a veces incomprensibles, violentas y esquivas; pero, sobre todo, experiencias que forman parte de la vida de sujetos marginados, cuyas voces tienden a ser objeto de apropiación por parte de discursos hegemónicos (liberales o de izquierda(s)), cuando no acalladas totalmente. ${ }^{22}$

La “voluntad realista” reconoce así que “esa realidad [...] es fragmentaria, [...] no tiene un significado estable ni abarcable, pero que, sin embargo, tiene cosas que decir” (Gaviria). Ello impone el "imperativo ético", que asume también una postura en torno al sentido político de la mirada: "El diálogo por el que todo el mundo clama sólo puede producirse después de la mirada y el conocimiento ético del Otro, que es la base de cualquier proyecto serio de paz y de reconstrucción de esta sociedad” (Gaviria). Jáuregui y Suárez aciertan cuando reflexionan sobre el efecto de esta perspectiva que entrega "la imagen del Otro [no como] simulacro puro (es decir, no es un dispositivo para la indiferencia)” (389), sino como un rostro que nos interpela en una "mirada-encuentro" (389). Surgen aquí una coincidencia

\footnotetext{
21 “El realismo de mis películas no es la narración costumbrista o truculenta, ni el documental”, afirma el director ("Violencia").

22 "Hago cine como una experiencia de conocimiento de mi tiempo, de mi ciudad, de la gente con la que vivo, y porque me apasiona la realidad, aunque la realidad a veces se muestre violenta e incomprensible, y aunque sea -ante todo- ocultamiento”, dice Gaviria (Jáuregui, "Violencia”).
} 
con Soy un delincuente, el testimonio de Santander-Brizuela, así como una diferencia con Soy un delincuente, la película de Clemente de la Cerda -quien, dicho sea de paso, deja escapar momentos de admonición distante o goce, frente a su tema de lo marginal.

Resaltar el proceso de producción de Rodrigo D. No futuro, frente a la película y el testimonio anteriores, permitirá comprender mejor cómo esta convergencia de voluntad realista y ética de la representación se articulan en la factura misma del cine de Víctor Gaviria. Como hemos visto en nuestra reflexión sobre el testimonio y la transposición cinematográfica, resulta complejo comparar dos textualidades tan disímiles. Mientras que el texto cinematográfico implica un largo proceso de trabajo colectivo, guiado sobre todo por un director, el texto literario-testimonial produce la colectivización a través de un efecto afín a la figura de la sinécdoque, donde un intelectual orgánico de una comunidad en estado de urgencia depone una historia de vida que representa, por una relación de contigüidad, a la totalidad del grupo. ${ }^{23}$

En este sentido, los textos que aquí discutimos plantean problemas interesantes. Un rasgo notable del testimonio Soy un delincuente radica en la capacidad de Gustavo Santander para seleccionar y combinar elementos de distintas historias, creando la voz de un individuo que, a su vez, revela los múltiples y disímiles niveles de la experiencia del delincuente. Por otro lado, la transposición cinematográfica realizada por Clemente de la Cerda tiende a unificar de manera más firme esta pluralidad, creando un personaje único y una voz homogénea, bajo la voluntad del director.

En el caso de Rodrigo D. No futuro, el procedimiento es contrario al que señalamos en la transposición realizada por Clemente de la Cerda y más próximo al texto literario de Santander. Víctor Gaviria se presenta sin duda como un director a la cabeza de un equipo de trabajo; sin embargo, logra que la voz de una pequeña colectividad -cuya cohesión se debe a la pobreza, las experiencias delictivas y la música punk- rebase la "visión artística" de su voluntad de autor. He allí el sesgo genial de Rodrigo D.: la impresión de que no estuviera guiada por una sola voluntad, sino múltiples. Es aquí donde encontramos una conexión con el texto indócil producido por Santander y las rugosidades que surgen ante la imposibilidad de anular la pluralidad de voces que lo integran.

A la luz de estas ideas resulta interesante recordar que el cine es el primer arte que deviene una gran industria capitalista, con la correspondiente división del trabajo. Asimismo, recordemos que, según Marx y C.L.R. James, la posibilidad de la emancipación humana del vampirismo del capital, del triunfo del trabajo vivo sobre el trabajo muerto, surge del proceso comunal del trabajo necesario para la producción del plusvalor. En ese sentido el cine podría ofrecer grandes posibilidades artísticas para una emancipación social lograda a través de la organización del trabajo colectivo.

Quisiéramos plantear, a manera de provocación, lo siguiente: lo distinto de una película como Rodrigo $D$. se debe, en parte, a la realización del potencial liberador del

\footnotetext{
${ }^{23}$ Véanse Beverley, Sommer. Usamos aquí el concepto de “deponer” sugerido por Juana Suárez para pensar el carácter legal de la acción de rendir testimonio. El intelectual orgánico, es decir, el sujeto testimoniante, depone o consigna su historia (y por extensión, la de su comunidad) ante un sujeto que posee acceso a los circuitos de producción y distribución de la escritura. En este sentido, la dimensión del trabajo colectivo es notablemente distinta en la literatura y en el cine testimonial.
} 
trabajo colectivo, que por lo general subyace latente en el cine debido a su sometimiento al gran capital. Víctor Gaviria y quienes lo acompañan contribuyen así a la ruptura del orden dominante de la representación, abriendo espacios para el punk y la delincuencia, con una rebeldía anárquica que, tanto en la vida como en la película, conduce a la muerte. Sin embargo, en este esfuerzo colectivo y subversivo, se ofrece sin duda alguna, una liberación momentánea.

El guión inicial de Rodrigo D. se titula El vuelo en el aire ${ }^{24}$ y está basando en una noticia periodística que relata el intento de suicidio de un joven que pretendió saltar desde un edificio en el centro de Medellín. Dicho guión fue apenas uno entre otros cuatro que fueron escritos, mientras la puesta en escena se modificaba por la desaparición de ciertos personajes, algunos asesinados durante el rodaje. Ello impuso una notable flexibilidad del guión, que permitía revisiones constantes. Existieron otros motivos que dieron origen a un texto tan singular. Primero, al escribir El vuelo en el aire, el joven director y guionista no había entrado en contacto con los muchachos del barrio que serían sus actores. Poco sabía de las cosas que pasaban en ese mundo y aún estaba por descubrir cómo relataban estos jóvenes sus experiencias. Segundo, el Medellín de esa época imponía una existencia tan efímera y cambiante que no se podía asegurar la continuidad de los actores como seres vivos en el tiempo y el espacio. Siendo así, los guionistas se vieron obligados a abrirse a la posibilidad del cambio abrupto y elegir como solución artística la entrada de nuevos personajes que imponían nuevas dinámicas dentro de la narrativa. ${ }^{25}$

Aunque los guionistas, incluyendo el director, ejercieron control sobre el proceso creativo en todo momento, lograron que los muchachos "los pelaos" se adueñaran de la película como algo propio; algo hecho desde adentro. Es posible que el rodaje de la película representara para muchos de ellos, su única participación en un proceso de trabajo colectivo, emancipador o no. Nada tenían que ver sus vidas laborales con las del proletariado socializado del que hablaba Marx o C.L.R. James, que se asemejaba al de sus padres, que una generación antes trabajaban masivamente en las fábricas de textiles. En definitiva, a diferencias de sus progenitores, estos jóvenes vivían, tanto en la vida real como en la película, sumergidos en el mundo de la delincuencia. ${ }^{26}$

El primer paso en la producción de Rodrigo $D$. fue, entonces, ir conociendo los barrios populares llamados comunas de Medellín. Gaviria contaba con el enlace de Juan Guillermo Arredondo, "Chiqui”, quien había crecido al lado de Barrio Triste, un núcleo clave de transporte y distribución de toda clase de mercancías y centro histórico del "malevo” en Medellín, cuando los sicarios todavía no existían, y los malos se llamaban "guapos” y mataban a cuchillazos. Chiqui se movía con soltura en el mundo de los "pillos" -personas sumergidas en la delincuencia y el consumo de drogas- y estaba escribiendo un libro de relatos sobre sus personajes, cuando convenció a Gaviria de que habría que representar

\footnotetext{
${ }^{24}$ Este primer guión fue premiado por el Ministerio de Cultura en 1986.

${ }^{25}$ Esta flexibilización del texto se pone en evidencia en los cambios en el título de la película. Carlos Mario Restrepo, el actor que fue asesinado el día en que lo invitaron a asistir a Cannes, había sugerido el nombre Vivir tanto sería la muerte; pero otro de los actores, El Alacrán, ingenió el de No futuro, que se quedó junto con el homenaje al maestro italiano del realismo.

${ }^{26}$ Habría que señalar aquí excepciones como en el caso del joven Meneses.
} 
la vida de los barrios de una forma más fiel a la violencia que en ellos se vivía. Ambos comenzaron a sentarse en grupo para escuchar historias de vida y muerte contadas por los jóvenes de la comuna nororiental, algunos de los cuales se convertirían en los actores de Rodrigo $D .{ }^{27}$ La disposición a escuchar estas múltiples versiones de la realidad barrial, así como la aceptación de estructuras y lenguajes que articulaban dichas narrativas desde adentro, permitió que la película alcanzara un “efecto realidad” que hemos vinculado a la huella de lo Real. ${ }^{28}$

A manera de resumen, podríamos decir que la decisión de trabajar con actores naturales de las comunas nororientales impuso ciertas pautas en la revisión del guión y la vida diaria durante el rodaje. Estos jóvenes dejaron su huella en la película, aunque es cierto que sin el trabajo de Víctor Gaviria, un sujeto de la clase media colombiana, hubiera sido difícil poner en escena tales experiencias. Es posible que el proceso de producción de Rodrigo $D$., radicalmente dialógico y muchas veces conflictivo, ayudase a los actores a conocer un nivel de libertad artística que pocos actores profesionales alcanzan en sus carreras -y vidas-, por cierto mucho más largas. Como director que orientó un proceso de trabajo colectivo, Gaviria supo canalizar una energía anárquica pero vital, sin imponerle un orden ajeno a su propia lógica. ${ }^{29}$ De allí que el resultado final sea una película que mira desde adentro, desde lo íntimo, lo doloroso e incluso lo lúdico de un universo frecuentemente obliterado, consumido en las representaciones de la porno-miseria o fosilizado en los cuadros de estadística estatal.

Como señalamos anteriormente, Rodrigo D. No futuro iba a titularse originalmente "Vivir tanto sería la muerte"; una cita textual tomada de Carlos Mario Restrepo, el actor callejero procedente del la comuna nororiental, quien interpreta a Adolfo en Rodrigo D. Como otros cinco actores del filme, Carlos Mario murió antes de que la película fuera distribuida. El 27 de marzo de 1989, el mismo día que recibió una invitación para asistir al Festival de Cannes, rivales de otro combo lo asesinaron.

Acribillado con seis balas y apuñalado 43 veces el día 19 de febrero del 2000, “el Zarco”, uno de los protagonistas del segundo filme de Gaviria, La vendedora de rosas (1998), había declarado en varias oportunidades su admiración por Carlos Mario. Cuando niño "el Zarco" miraba con respeto a Carlos Mario por ser un actor de la calle que había vivido lo que retrataba Rodrigo D. Doña Magnolia Tabares, quien interpretó el papel de madre de "el Zarco" en La vendedora de rosas, era la madre del ya difunto Carlos Mario

\footnotetext{
${ }^{27}$ Los datos sobre la producción de Rodrigo $D$. fueron obtenidos gracias a una entrevista con Juan Guillermo Arredondo (Chiqui), diciembre 2004. Antes de rodar, el director y los que harían con él los siguientes borradores del guión pasaron varios meses sumergidos en el mundo que representarían con cámara. Conocieron las historias de vida de cada uno de los actores, consumieron drogas con ellos (si no lo hubieran hecho, habría sido percibido como un rechazo a sus gustos y placeres). El equipo sabía de los problemas que cada uno tenía en su barrio o con la ley. Por eso supieron que no iba a ser posible rodar en la Comuna Nororiental, de donde provenían los actores, pues todos menos Meneses tenían allí enemigos, nombrados en su jerga con el término homoerótico de "enemoraaos”. Tenían así que resolver problemas inmediatos que surgían de la cotidianidad de los actores.

${ }^{28}$ En esto "Rodrigo D.” tiene afinidades con el testimonio, género al que Víctor Gaviria ha aportado con El pelaíto que no duró nada.
}

${ }^{29}$ Entrevista de Luis Duno-Gottberg con Víctor Gaviria, Fort Lauderdale 2005. 
Restrepo. Cuando se le preguntó acerca de la vida y muerte de jóvenes como Carlos Mario y “el Zarco”, Doña Magnolia dijo: "Son muchachos que presienten la muerte, porque han vivido en la violencia. Sabían que no tenían la vida segura, pero les gustaba la calle, el riesgo. En la calle se encuentran los vicios y también algunos amigos” (El Colombiano, 27 febrero 2000).

Tras el asesinato de "el Zarco", periodistas de El Colombiano, el principal diario de Medellín, le preguntaron a Gaviria sobre el hecho de que todos menos dos de los actores de su primera película, y otros tantos de su segunda, han muerto en las calles. Gaviria respondió: "El problema no es de las películas, ni de Víctor ni de ellos como actores, sino de la juventud que es asesinada sistemáticamente, abandonada a una guerra social que a nadie interesa" (Gaviria en Spitaletta). ${ }^{30}$

Aquí cabe preguntarse por los efectos del realismo en la representación de este universo de la violencia dentro del cine contemporáneo. ¿Acaso el hecho de que Carlos Mario Restrepo fuera asesinado el mismo día que recibió una invitación para Cannes pueda leerse dentro de esa "lógica cultural del capitalismo tardío" que impulsa la ahistoricidad de la metrópolis y el decrecimiento del afecto? En otras palabras, ¿cuáles serían las implicaciones políticas de la relación entre "la voluntad de verdad” de Gaviria, el contexto ultraviolento que aprehende, y la recepción crítica en los países noratlánticos? ¿Cómo media esta relación la "forma-mercancía" que venimos analizando?

Para hallar respuestas debemos enfocarnos en la trinidad de producción, consumo y distribución, términos que Paul Gilroy ha descrito como áridos, ya que "no le hacen justicia a los procesos transnacionales a los cuales se refieren” (103). Es decir, necesitamos construir un puente entre la división artificial disciplinaria que ha acordonado la crítica de la economía política de los estudios culturales, pero sin limitarnos al horizonte del estado-nación.

La inserción de películas realizadas en las comunas de Medellín -una de las aglomeraciones urbanas más "peligrosas” y políticamente conflictivas del mundo- en los circuitos de distribución, consumo y comentarios noratlánticos, tiende a borrar la particularidad concreta de su dimensión histórica. Tanto Rodrigo D. como La vendedora de rosas se basan en la vida de jóvenes reales que, como hemos señalado, se pusieron en escena a partir de la negociación de un espacio de representación con el director de las películas. Sin embargo, no podemos olvidar que muchos no vivieron para cumplir los 25 años. Si el Estado/para-Estado (policía, paramilitares, ejército) no los asesinaba, ellos lo hacían, unos a otros, atrapados por la paranoia, sus propias riñas, la venganza y la sed de muerte.

Sin ningún sentido de contexto, este horror aparece fortuito y desesperanzado. "El otro” proveniente de las zonas urbanas de capitalismo neocolonial, es asimilado con "el otro” proveniente de la minoría criminalizada de las metrópolis imperiales: trabajadores inmigrantes, enfermos mentales, indigentes, jóvenes africanos y latinos, adictos. Esta es precisamente la equivalencia abstracta a la cual Marx se refería: parte de la magia del valor,

\footnotetext{
${ }^{30}$ Incluso las miradas más superficiales, como los indicadores estadísticos, señalan una de las tasas de homicidios más altas del mundo desde 1986. Los registros de derechos humanos, por su parte, arrojan un estimado de diez a doce asesinatos políticos por día durante la última década. Todo ello confirma las palabras de Gaviria sobre Medellín, así como las de Salazar en lo concerniente a la relación entre la guerra que se libra en Medellín con la del resto de Colombia.
} 
el cual "no tiene su descripción marcada en su frente" y aun transforma "cada producto de trabajo en un jeroglífico social” (Marx I, 167). En el "mapa cognitivo” del paisaje global imaginario, marcado por el miedo y la ansiedad, los espectadores de las metrópolis establecen una relación de equivalencias entre, digamos, Medellín, Kingston y Los Ángeles. Todos éstos devienen lugares igualmente caracterizados por una guerra entre bandas y violencia intra-clase de gente de color. A partir de allí no habría necesidad de reflexionar sobre la totalidad social jerarquizada en la que están envueltos todos.

Sin embargo, más allá de estos riesgos que conlleva este tipo de consumo trasnacional, es claro que el trabajo de Víctor Gaviria persigue fines distintos a los de la mera contemplación vicaria o deshistorización del fenómeno de la violencia. Ello se evidencia en la construcción colectiva del guión que hemos discutido antes y en la apelación a un contexto absolutamente específico y regional que se encuentra históricamente marcado para las audiencias colombianas.

Gaviria representa momentos concretos de lo que el economista colombiano Salomón Kalmanovitz ha llamado “capitalismo salvaje”. Por ejemplo, Rodrigo D. está profundamente enraizada en la historia y la geografía colombianas. Desde los 40s la desposesión violenta en el campo ha llevado a millones de migrantes a la periferia de Medellín y otras ciudades en busca de un trabajo que no encontrarán. ${ }^{31}$ Metafóricamente hablando, Rodrigo y Gustavo son los nietos de "Desquite", un legendario líder de las guerrillas liberales durante La Violencia de los años cincuenta a los sesenta, a quien el poeta paisa Gonzalo Arango se refirió en el siguiente pasaje: ${ }^{32}$

\begin{abstract}
En uno de los ocho agujeros que abalearon el cuerpo del bandido, deposito mi rosa de sangre. Uno de esos disparos mató a un inocente que no tuvo posibilidad de serlo. Los otros siete mataron al asesino que fue...YYo pregunto sobre su tumba cavada en la montaña: ¿ No habrá manera de que Colombia en vez de matar a sus hijos los haga dignos de vivir? Si Colombia no puede responder a esta pregunta, entonces profetizo una desgracia: “Desquite” resucitará, y la tierra se volverá a regar de sangre, dolor y lágrimas. (Salazar 109)
\end{abstract}

En una entrevista sobre "guerra social” y el "asesinato sistemático” de jóvenes pobres en las comunas, Gaviria señaló la inseparabilidad del texto y contexto en su trabajo. ${ }^{33}$ Carentes del mínimo entendimiento del contexto, los espectadores noratlánticos están más propensos a fetichizar la violencia, aplanar y negar sus profundidades históricas, efectuando así un divorcio entre el producto artístico terminado y su proceso de elaboración. Por esta última razón, cabría decir que más allá de los aciertos de este cine, "la huella de lo Real” continúa siendo, en última instancia, no menos elusiva que lo Real mismo.

\footnotetext{
${ }^{31}$ Véanse Roldán y Marx.

${ }^{32}$ Sobre "Desquite”, véase Sánchez y Meertens 129-56.

${ }^{33}$ Entrevista de Forrest Hylton con Victor Gaviria, abril 2000.
} 
IV. NO NACIMOS PA' SEMILLA

Estuve quince días que no pude comer porque veía el
muerto hasta en la sopa...pero después fue fácil.

No nacimos pa' semilla

Alonso Salazar publicó No nacimos pa'semilla en 1990, el mismo año en que Rodrigo $D$. fue estrenado en Cannes. Esta coincidencia temporal no parece gratuita y conecta la violencia representada por Víctor Gaviria con una serie de testimonios que, desde ópticas distintas, dan cuenta de la intensificación de los conflictos políticos y sociales que venimos discutiendo. El libro es una compilación de voces heterogéneas que registra la fuerza homicida de las milicias populares, las bandas y los combos delincuenciales que convirtieron a Medellín en una capital mundial del asesinato. Salazar explica el fenómeno representado de la siguiente manera:

La violencia es una parte de la realidad de Medellín, vivimos en una ciudad en guerra. Una guerra donde intervienen muchos poderes y donde los protagonistas son los jóvenes. Ellos son los que matan y mueren. Ejecutantes de un libreto escrito por otras manos e inspirado en el sentido trágico que sigue marcando nuestra historia....Medellín es un hervidero de vida y muerte, es una expresión radical de la crisis del país. (Salazar 17)

No nacimos pa'semilla permite de esta manera comprender el desarrollo en el tiempo y el espacio de esa guerra que arrebató la vida de los actores principales, menos dos, de Rodrigo $D$. Otras conexiones surgen de la recepción de ambos trabajos: tanto el libro como la película tuvieron un impacto notable en el "público nacional”, definido aquí como la gente urbana de clase media, con ciudadanía plena en una república excluyente. Asimismo, al igual que la película de Gaviria, el libro alcanzó un público internacional y fue traducido al inglés por la editorial Latin American Books de Londres, en 1992.

A diferencia de la película, sin embargo, el texto de Salazar no fue el resultado de un proceso de trabajo colectivo, sino de un esfuerzo individual/institucional. En primer lugar, fue producido bajo el auspicio de la Corporación Región, un organismo no gubernamental para el desarrollo social de la juventud y la protección de los derechos humanos. En segundo lugar, el locus de la enunciación desde el cual se articula el proyecto de la edición -a diferencia de las voces que se pronuncian en ella- puede caracterizarse como propio del intelectual académico de clase media, que si bien habla con los subalternos y les permite expresarse, también impone cierto "principio de coherencia", en correspondencia con su noción de orden. Principio éste que resulta con frecuencia ajeno a los individuos que relatan su participación en la violencia.

En una caracterización de estas voces, es interesante apuntar que, en general, parecen resistentes a cualquier clase de recuperación política para un proyecto de emancipación. De hecho, algunas tienen tendencias marcadas hacia una política de derecha, lo que parece surgir de su apego al capitalismo de los “comerciantes” paisas. Debido en parte al florecimiento de la guerra urbana en Medellín, 40 mil jóvenes entre los 14 y los 25 años han muerto violentamente desde 1986. Tras el colapso de los diálogos de paz entre la administración 
conservadora de Belisario Betancur y las FARC, EPL y el M19 entre1985-86, Medellín se convirtió en la capital mundial del homicidio, sobrepasando a Cali, su más próximo rival (Bushnell 252). ${ }^{34} \mathrm{~A}$ lo largo de la periferia de la ciudad se repetía una y otra vez la disputa por territorios entre las milicias de izquierda y las bandas callejeras, desde que ambas comenzaron a proliferar a finales de los ochenta y comienzos de los noventa (Ceballos 110-31).

Esta guerra urbana estaba, y está, íntimamente ligada a la contrainsurgencia rural. En el campo antioqueño y en Medellín, entre 1987-88, un bloque de ultraderecha compuesto por ganaderos, jefes del Partido Liberal, miembros dirigentes de la inteligencia militar y narcotraficantes, ganó terreno a través del asesinato selectivo de políticos de oposición pertenecientes a la UP (Unión Patriótica), estudiantes, profesores, campesinos y mineros, especialmente en el Magdalena Medio, al noreste de Antioquia (Segovia, Remedios, Zaragoza) y en el mismo Medellín. ${ }^{35}$ Los paramilitares desplazaron a miles de personas del campo, quienes buscaron refugio en Medellín, sólo para encontrarse ellos mismos -y, crucialmente, su descendencia- atrapados en una nueva dinámica del conflicto. Se trata de un fenómeno que afecta tanto la frontera agrícola, como en la frontera urbana, y que William Ramírez ha llamado “la colonización armada” y la disputa por el control y manejo del territorio. ${ }^{36}$

Pese a que la guerra urbana entre bandas y milicias se libraba cuadra a cuadra, los conflictos barriales locales involucraron actores de nivel nacional, como algunas de las bandas que habían tenido vínculos con Pablo Escobar y otras que habían estado vinculadas a los órganos represivos del Estado colombiano. Estos últimos usaron a los antiguos socios de Escobar, varios de ellos devotamente anticomunistas como los hermanos Castaño, para destruirlo en $1993 .{ }^{37}$ Por su parte, algunas milicias, si bien no todas, habían tenido vínculos con los mayores grupos guerrilleros, FARC y ELN. ${ }^{38}$ Estas milicias operaban principalmente en barrios de población desplazada, en el abismo de la ciudad, mientras que otras, de carácter independiente, florecieron a lo largo de Medellín, descendiendo de las lomas al centro.

Como lo revelan algunos testimonios recogidos en No nacimos pa'semilla, las milicias van degenerado en corrupción y autoritarismo. Esto deviene evidente más tarde, a mediados de los noventa, cuando pierden progresivamente el apoyo popular. Como consecuencia, muchos se reagruparan en torno a las bandas a las cuales habían pertenecido alguna vez. Aquellas milicias que no tomaron el camino de las negociaciones abiertas por el gobernador Gilberto Echeverri, quien en 1990 envió al presidente Gaviria un mensaje sobre una próxima

\footnotetext{
${ }^{34}$ En 1973, el homicidio era la séptima causa más importante de mortalidad. Para una visión cuantitiva sobre homicidio y el crimen violento en los setentas y ochentas, véase Camacho y Guzmán; para los noventas véase Villaveces 275-80; para las cifras sobre Medellín, véase Jaramillo et al., 111.

${ }^{35}$ Véanse Medina Gallego; Reyes Posada, “Conflicto...” y “Propiedad...” 23-33; Cubides 127-50.

${ }^{36}$ Véanse Ramírez Tobón 199-209; Cubides, Colonización...; Molano Bravo, “Voice...” 195-216 y “Algunas...” 27-41.

${ }^{37}$ Sobre “los pepes”, véase Salazar, La parábola de Pablo 307-14.

${ }^{38}$ Sobre el crecimiento rápido de las guerrillas, véase Chernick y Jiménez 61-82. Sobre las FARC, véanse Alape; Pizarro Leongómez; y Molano. Sobre el ELN, véanse Medina Gallego, ELN: una historia en dos voces contadas; Calvo Ocampo; y Broderick.
} 
toma de la ciudad por parte de comunistas, fueron rápidamente infiltradas. ${ }^{39}$ Para la segunda mitad de los noventas, las bandas ya habían recuperado el terreno perdido. Durante el régimen del gobernador de Alvaro Uribe Vélez, de 1995-97, se legalizaron las oscuras e informales alianzas políticas conformadas entre bandas, carteles de la droga, paramilitares y la IV Brigada del ejército bajo la forma de CONVIVIR. Con ello, las milicias experimentaron su más alta decadencia. ${ }^{40}$

En los barrios donde Gaviria rodó gran parte de Rodrigo D., las comunas noroccidentales, las milicias populares controlaban algunos barrios, especialmente los más periféricos. Pablo Escobar, a su vez, controlaba otros por medio de bandas como "Los Priscos”. Actualmente, el sector está bajo régimen de los paramilitares de Diego Fernando Murillo, aka “Don Berna”, aka “Adolfo Paz”, fundador de la banda más temida de la historia de Medellín, “Los de la Terraza”. La escena en Rodrigo D. en la cual los pela'os van en busca de escondite para escapar de la policía/paramilitares fue filmada en las comunas centro-orientales en donde Pablo Escobar, quien se autodenominaba un empresario rebelde, construyó casas para “el pueblo” mientras Alvaro Uribe Vélez era alcalde de Medellín en 1982. Esta compleja y fluida “realidad” de la guerra urbana en Medellín ha sido incorporada en la obra de Gaviria a través de Rodrigo D., La vendedora de rosas y su película más reciente, Sumas y restas.

Aunque dejamos de lado una reflexión profunda sobre el hecho, cabe mencionar que con el triunfo electoral del candidato independiente para la alcaldía de Medellín, Sergio Fajardo (2003), el redactor de No nacimos pa'semilla se convirtió en Secretario de Gobierno, ejerciendo sus funciones en una ciudad donde los poderes paraestatales son notablemente fuertes. El testimonio que hizo famoso a Alonso Salazar como investigador de la realidad contemporánea colombiana registra precisamente esos múltiples poderes que han crecido como un cáncer en los años posteriores a su publicación. Esto nos obliga a matizar nuestro juicio sobre el lugar que ocupa el autor como Secretario de Gobierno y luego como Alcalde (2007), frente a un proyecto de representación de los márgenes de la sociedad colombiana. Si bien en una primera instancia se podría pensar que la carrera de Salazar es un caso claro de cooptación del intelectual progresista por parte del aparato, a la vez más compacto y más diluido que es el Estado, resulta más complejo en el contexto particular que nos interesa.

Cabria entonces plantearse dos preguntas. En primer lugar, si resulta posible enfrentar desde el Estado a los poderes paraestatales descritos por las voces de No nacimos pa'semilla. La respuesta parece negativa, a juzgar por los resultados del proceso de desmovilización. ${ }^{41}$ En segundo lugar, si el proyecto detrás del testimonio supone realmente una apertura hacia/ desde el margen o una instrumentalización de la voz del Otro en torno a un programa más

\footnotetext{
${ }^{39}$ Entrevistas de Forrest Hylton con exmilicianos y milicianos activos, junio 1999; mayo 2000; julio 2002.

${ }^{40}$ Véase Cubides, "From Private to Public Violence...” 131. Las CONVIVIR fueron declaradas ilegales en 1999 pero siguen funcionando abiertamente en Medellín. Tal vez el componente más importante de los acuerdos firmados entre el gobierno y varias milicias fue la incorporación de líderes milicianos en la administración pública como jefes de cooperativas de seguridad. Ver Téllez Ardilla 107. ${ }^{41}$ Véase Hylton 71-89.
} 
ambiguo. No nacimos pa'semilla plantearía así una serie de problemas singulares, en tanto recoge las miradas/voces de un margen ultra-violento, así como la posible intersección con un proyecto estatal y acaso paraestatal.

\section{ConClusión}

En 1977, Luis Ospina y Carlos Mayolo proponen una ruptura con lo que se había convertido en una fórmula de producción cinematográfica para el tercer mundo: el miserabilismo o lo que denominaron la porno-miseria. Con su documental $-\mathrm{o}$ antidocumental-Agarrando pueblo, Ospina y Mayolo desmontan una industria que se entregaba a los hábitos de consumo de las metrópolis, las cuales esperaban una producción continua de imágenes sobre la pobreza y los horrores del tercer mundo. Agarrando pueblo acompaña a un equipo documentalista por las calles de Cali, mientras persigue a un grupo de "sujetostemas” ideales: locos, pordioseros, gamines. Como señala Cruz Carvajal, se trata de una respuesta contestataria de directores que persiguen un nuevo proyecto de representación: "Crear directamente con las personas, y no acomodar a esquemas de exportación regidos, entre otras industrias, por la del cine "bien hecho'” (3). Esta temprana advertencia parece resonar de modos distintos en los textos que hemos analizado. Clamente de la Cerda y Víctor Gaviria, Gustavo Santander y Alonso Salazar ya no parecen conformar un corpus unificado sobre el testimonio de la delincuencia. Sutiles diferencias anuncian agendas de representación diversas.

En Soy un delincuente, de Brizuela/Santander, el fracaso de la literatura es el éxito del testimonio. En Soy un delincuente, de Clemente de la Cerda, el éxito del cine constituye un fracaso de lo testimonial. En Rodrigo D. No futuro, de Víctor Gaviria, los límites de la voluntad autoral del director determinan los éxitos de lo testimonial. Mientras que en No nacimos pa'semilla, de Alonso Salazar, los éxitos del testimonio parecen apetecibles al aparato de estado.

Finalmente, queremos proponer la posibilidad de que, más allá del secreto discutido por Doris Summer en su trabajo sobre Menchú, existen otras marcas textuales de esa otredad irreductible que habita narrativas resistentes o indóciles. Esto permite pensar en textos que pueden no ser siempre consumidos cómodamente desde una posición hegemónica o, incluso, desde la solidaridad con el subalterno. Creemos que ciertos discursos de la delincuencia que parten del testimonio, como el caso de Soy un delincuente y Rodrigo D., pueden ofrecer un ejemplo singular de instancias en las que la narrativa tiende a resistir la mera abyección o la fetichización. Se pone en evidencia lo que denominamos la traza de lo Real, que quizás caracteriza narrativas indóciles o resistentes y que, sobre todo, marca el lugar de una imposibilidad; de lo que Giorgio Agamben denomina "una laguna” y que, como hemos observado en el caso de Rodrigo D. y No nacimos pa'semilla, constituye una traza frágil, siempre susceptible de ser borrada por ciertos hábitos de consumo. 
BiBLIOGRAFÍA

Alape, Arturo. Tirofijo: los sueños y las montañas, 1964-1984. Bogotá: Planeta, 1994.

Bazin, André. What is Cinema? Berkeley: U of California P, 1971.

Beverley, John. Del Lazarillo al Sandinismo: estudios sobre la función ideológica de la literatura española e hispanoamericana. Minneapolis: Institute for the Study of Ideologies and Literature, 1987.

"Introducción”. La voz del otro: testimonio, subalternidad y verdad narrativa. John Beverley y Hugo Achugar, eds. Revista de crítica literaria latinoamericana 36 (1992): 7-18.

“The Real Thing”. The Real Thing. Testimonial Discourse and Latin America. George M. Gugelberger, ed. Durham: Duke UP, 1996. 266-87.

Birri, Fernando. “Cine y subdesarrollo”. Hojas de Cine. Testimonios y documentos del Nuevo Cine Latinoamericano. México: Fundación Mexicana de Cineastas, 1988.

Brizuela, Ramón. Soy un delincuente. Caracas: Editorial Fuentes, 1974.

Broderick, Walter J. El guerrillero invisible. Bogotá, 2000.

Bushnell, David. The Making of Modern Colombia: A Nation in Spite of Itself. Berkeley: U of California P, 1993.

Calvo Ocampo, Fabiola. Manuel Pérez: un cura español en la guerrilla colombiana. Madrid: Vosa, 1998.

Camacho, Alvaro y Alvaro Guzmán. Ciudad y violencia. Bogotá: Ediciones Foro Nacional, 1990.

Carroll, Noel. “Nonfiction Film and Postmodern Skepticism”. Post-Theory. Reconstructing Film Studies. David Bordwell y Noel Carroll, eds. Madison: The U of Wisconsin P, 1996. 37-68.

Caruth, Cathy. "Recapturing the Past: Introduction”. Trauma: Explorations in Memory. Cathy Caruth, ed. Baltimore: Johns Hopkins UP, 1995. 151-57.

Castillo, Fabio. Los jinetes de la cocaína. Bogotá: Ed. Documentos Periodísticos, 1988.

Ceballos Melguizo, Ramiro. “The Evolution of Armed Conflict in Medellín: An Analysis of Major Actors”. Latin American Perspectives 28/1 (January 2001): 110-131.

Chernick, Marc W. y Michael F. Jiménez. "Popular Liberalism, Radical Democracy, and Marxism: Leftist Politics in Contemporary Colombia, 1974-1991”. The Latin American Left: From the Fall of Allende to Perestroika. Barry Carr y Steven Ellner, eds. Boulder: Westview Press, 1993. 61-82.

Cisneros, Carmen Luisa. “Tiempos de avance: 1959-1972”. Panorama Histórico del Cine en Veneuela. Caracas: Cinemateca Nacional de Venezuela, 1997. 129-51.

Cohen, Stanley. Devils and Moral Panic. Londres: Routledge, 2003.

Cubides, Fernando, et al. Colonización, coca, y guerrilla. Bogotá: Alianza Editorial Colombiana, 1989.

"From Private to Public Violence: The Paramilitaries". Violence in Colombia, 19902000: Waging War and Negotiating Peace. Charles Bergquist, et al. Wilmington, DE: Scholarly Resources, 2001. 127-50.

Currie, Gregory. "Film, Reality, and Illusion”. Post-Theory. Reconstructing Film Studies. David Bordwell y Noel Carroll, eds. Madison: The U of Wisconsin P, 1996. 325-44. 
Gutiérrez Alea, Tomás. Dialéctica del espectador. La Habana: Ediciones Unión, 1982.

Dabove, Juan Pablo. "El debate de las armas y las letras en el testimonio de delincuentes. El caso de Soy un delincuente, de Ramón Antonio Brizuela”. Actas del XX Congreso de Literatura Española y Latinoamericana. Washington DC: Montclair State University, 1999. 37-52.

Duno-Gottberg, Luis, ed. Miradas al margen. Cine y Subalternidad en América Latina. Caracas: Cinemateca Nacional de Venezuela, 2008.

Duque, José Roberto y Boris Muñoz. La ley de la calle [1992]. Caracas: FundArte, 1995.

Gaviria, Víctor. "Víctor Gaviria por Víctor Gaviria”. Entrevista con Fernando Cortés. $<$ www.revistanumero.com/18victor.htm>

Gilroy, Paul. The Black Atlantic. Cambridge: Cambridge UP, 1990.

Hylton, Forrest. “Remaking Medellin”. New Left Review 44 (March-April, 2007): 71-89. James, C.L.R. Facing Reality. Detroit: Bewick Editions, 1956.

Jara, René. “Prólogo”. Testimonio y literatura. René Jara y Hernán Vidal, eds. Minneapolis: Institute for the Study of Ideologies and Literature, 1986. y Nicolás Spadaccini, eds. Testimonio y literatura. Minneapolis: Institute for the Study of Ideologies and Literature, 1986.

Jaramillo, Ana María, et al. En la Encrucijada: Conflicto y cultura política en Medellín de los noventa. Medellín: Corporación Región, 1998.

Jáuregui, Carlos. "Violencia, representación y voluntad realista”. Entrevista con Víctor Gaviria. Espacio urbano, comunicación y violencia en Latinoamérica. Pittsburgh: IILI-Serie Tres Ríos, 2002. 223-35.

y Juana Suárez. "Profilaxis, traducción y ética: la humanidad 'desechable’ en Rodrigo D. No futuro, La vendedora de rosas y La virgen de los sicarios”. Revista Iberoamericana LXVIII/199 (abril-junio 2002): 367-92.

Kantaris, Elia Geoffrey. "Allegorical Cities: Bodies and Visions in Colombian Urban Cinema”. Estudios Interdisciplinarios de América Latina y el Caribe IX/2 (juliodiciembre 1998). <http://www.tau.ac.il/eial/ix_2/index.html\#articulos>

Krakauer, Siegfried. Theory of Film: The Redemption of Physical Reality. Nueva York: Oxford UP, 1960.

Kristeva, Julia. The Powers of Horror. An Essay on Abjection. Nueva York: Columbia UP, 1982.

López, Ana M. “At the Limits of Documentary: Hypertextual Transformation and the New Latin American Cinema”. The Social Documentary in Latin America. Juliane Burton, ed. Pittsburgh: U of Pittsburgh P, 1990. 407-8.

López, Magdalena. “La estética del 'balurdo': La propuesta de los filmes Soy un delincuente y Reincidente. Manuscrito no publicado. 16-12-2004.

Marx, Karl. Capital [1867]. Vol. 1. Nueva York: Penguin, 1992.

Medina Gallego, Carlos. Autodefensas, paramilitaries y narcotráfico en Colombia: origen, desarrollo y consolidación. El caso de Puerto Boyacá. Bogotá: Documentos Periodísticos, 1990.

ELN: una historia en dos voces contadas. Bogotá: Rodríguez Quito Editores, 1996. 
Menchú, Rigoberta. Me llamo Rigoberta Menchú y así me nació la conciencia. México: Siglo Veintiuno Editores, 1994.

Mesa, Beatriz et al. "El Zarco, Mónica, Elkin, Alex, Carlos Mario, John...Muertos de película”. El Colombiano (27 de febrero de 2000).

Molano, Alfredo. Trochas y fusiles. Bogotá: El Áncora, 1994.

Molano Bravo, Alfredo. "Violence and Land Colonization”. Violence in Colombia: The Contemporary Crisis in Historical Perspective. Charles Bergquist, et al. Wilmington, DE: Scholarly Resources, 1992. 195-216.

“Algunas consideraciones sobre colonización y violencia”. El agro y la cuestión social. Catherine LeGrand, et al. Bogotá: Tercer Mundo, 1994. 27-41.

Moreiras, Alberto. “The Aura of Testimonio". The Real Thing. Testimonial Discourse and Latin America. Georg M. Gugelberger, ed. Durham: Duke UP, 1996. 192-225.

Nichols, Bill. La representación de la realidad. Cuestiones y conceptos sobre el documental. Barcelona: Paidós, 1997.

Pizarro Leongómez, Eduardo. Las FARC, 1949-1966. Bogotá: Tercer Mundo, 1991.

Plantinga, Carl. "Moving Pictures and the Rhetiric of Nonfiction: Two Approches". PostTheory. Reconstructing film Studies. David Bordwell y Noel Carroll, eds. Madison: The U of Wisconsin P, 1996. 307-25.

Ramírez Tobón, William. "La guerrilla rural en Colombia: ¿una vía hacia la colonización armada?” Estudios Rurales Latinoamericanos 4/2 (1981): 199-209.

Reyes Posada, Alejandro. "Conflicto armado y territorio en Colombia”. Colonización del bosque húmedo tropical. Bogotá: s/e, 1989.

"Propiedad de la tierra y narcotráfico en Colombia”. La nueva historia de Colombia. Vol. VIII. Álvaro Tirado Mejía, ed. Bogotá: s/e, 1995. 23-33.

Rich, B. Ruby. “An/Other View of the New Latin American Cinema”. New Latin American Cinema: Theory, Practices, and Transcontinental Articulations. Vol. I. Michael T. Martin, ed. Detroit: Wayne State UP, 1997. 273-97.

Roldan, Mary. Blood and Fire: La Violencia in Antioquia Colombia, 1946-53. Durham: Duke UP, 2002.

Salazar, Alonso. La parábola de Pablo: auge y caída de un gran narcotraficante. Bogotá: Planeta, 2002.

No nacimos pa’ semilla. Bogotá: Cinep, 1990.

Sánchez, Gonzalo y Donny Meertens. Bandoleros, gamonales, y campesinos. Bogotá: El Áncora, 1983.

Spitaletta, Reinaldo, Beatriz Mesa y Rodrigo Martínez. “El Zarco, Mónica, Elkin, Alex, Carlos Mario, John... Muertos de película”. El Colombiano (Medellín, 27 de febrero de 2000).

Spivak, Gayatri. “Can the Subaltern Speak?” Marxism and the Interpretation of Culture. Cary Nelson y Lawrence Grossberg, eds. Urbana: U of Illinois P, 1988. 271-313.

Sommer, Doris. "Sin secretos". Revista de crítica literaria latinoamericana XVIII/36 (1992): 135-53.

Téllez Ardilla, Astrid Mireya. Milicias populares: otra expresión de la violencia social en Colombia. Bogotá: Rodríguez Quito, 1995. 
Villaveces, Andrés. “Appendix: A Comparative Statistical Note on Homicide Rates in Colombia”. Violence in Colombia, 1990-2000: Waging War and Negotiating Peace. Charles Bergquist et al. Wilminton, DE: Scholarly Resources, 2001. 275-80.

Yúdice, George. “Testimonio and Postmodernism”. The Real Thing. Testimonial Discourse and Latin America. Georg M. Gugelberger, ed. Durham: Duke UP, 1996. 42-58.

“Testimonio y concientización”. La voz del otro: testimonio, subalternidad y verdad narrativa. John Beverley y Hugo Achugar, eds. Revista de crítica literaria latinoamericana 36 (1992): 207-227.

Žižek, Slavoj. The Sublime Object of Ideology. Londres: Verso, 1989. On Belief. Londres: Routledge, 2001. 